\title{
THE GENERAL PATTERN OF SEASONAL DYNAMICS OF THE AUTUMN MIGRATION OF THE WOOD PIGEON COLUMBA PALUMBUS IN ITALY
}

\author{
Enrico Cavina, Rinaldo Bucchi and Przemysław Busse
}

\begin{abstract}
Cavina E., Bucchi R. and Busse P. 2018. The general pattern of seasonal dynamics of the autumn migration of the Wood Pigeon Columba palumbus in Italy. Ring 40: 3-18.

Given the scarcity of studies on the migration of the Wood Pigeon through Italy, the first systematic observations by a network of hunters, as citizen researchers, can be presented as a starting point for more in-depth analyses. Observations from the years 1998-2006 are analysed and presented in a generalized form. During this period more than 100 observation sites, covering most of Italy, were active for about 40 days every autumn. Migration over Italy was described in terms of the timing and intensity of migration. Special attention was directed to the long-term number dynamics and seasonal dynamics of the passage. The most intensive migration was observed within northern Italy, while lower intensity is visible more to the south of the peninsula. Following tendencies in numbers of observed migrants within the ten years of the study, we can find positive tendencies in most of the northern provinces, while three negative trends are visible in central Italy. The study of the seasonal pattern, in terms of the number dynamics of the passage and the frequency of pronounced peak days, strongly suggests that there are five or six waves of pigeons passing through Italy in different parts of the autumn that are quite stable between years. Every year the time of the passage includes a few peak days of migration.
\end{abstract}

E. Cavina, Club Italiano de Colombaccio, via Serraloggia 31, 60044 Fabiano (An), Italy; R. Bucchi, Club Italiano de Colombaccio, Italy; P. Busse (corresponding author), Bird Migration Research Foundation, Przebendowo 3, 84-210 Choczewo, Poland, e-mail: busse@wbwp-fund.eu

Keywords: seasonal migration pattern, autumn, migration peaks, migration waves, Wood Pigeon, Italy

\section{INTRODUCTION}

Italy is a peninsular bridge through the Mediterranean Sea, between the European continent and the North African and Spanish coasts $\left(35-47^{\circ} \mathrm{N}, 6-18^{\circ} \mathrm{E}\right)$. It is divided into Continental Italy (at $44^{\circ} \mathrm{N}$ ), Peninsular Italy and Insular Italy. The Alps (barrier at the Continental North) and Apennine Mountains and their foothills, rivers 
and valleys are clear markers of the complex topography and hydrography of Italy and determine its seasonal climatology and weather.

Autumn migration of wood pigeons takes place mainly in October, but also during the first half of November. Wood pigeons arrive mostly from the eastern continental parts of Europe and western parts of the Asiatic Palearctic (Hobson 2009). This migratory route begins in Eastern Europe, Russia and Ukraine, but probably also in Asiatic areas east of the Urals. The breeding origin of many populations of wood pigeons arriving in Italy remains a problem to be better investigated.

The main route of migration from Eastern countries passes through Hungary, Slovenia, Austria and Croatia, and enters Italy by what is known locally as 'the East Italian Gate' in the region of Friuli Venezia Giulia, which includes the Carniche Alps and the Tagliamento and Fella River valleys. This corridor gives flying migrants direct access to continental Italy - the Po valley, south of the Alps up to the Maritime Alps, and the coast on the French border in the west and the Ligurian Sea (Genoa) in the south.

It should be emphasized that several different populations migrate through Italy: those that breed a great distance away, within eastern Russia, as well as others breeding in the forests of the Carpathian Mountains and the Balkans. These can all have different lengths of migration: they can be long-, medium-, or short-distance migrants. Thus the seasonal pattern of migration could be varied in terms of timing and intensity.

The seasonal phenomenon of migration is an important part of the historical tradition and culture of many thousands of Italian hunters. For this group of citizens, knowledge of migration has been limited to practical, uncoordinated observations, but for twenty years an idea has been developing among hunters to conduct systematic daily observations for potential scientific use. A better understanding of the properties of the migration may be useful in the practice of sustainable exploitation of huntable bird resources.

The aim of this paper is to provide a general picture of the autumn migration of this species in Italy and to suggest subsequent research for elucidating this phenomenon. This could encourage the formation of a network of observation sites maintained by birders and hunters.

\section{MATERIAL AND METHODS}

The source of the data is reports from Progretto Colombaccio (R. Bucchi) and Progetto Colombaccio Italia (S. Giannerini). Examples of the data are presented in Figures 1 and 2. The observation scheme was launched in 1997 and carried out until 2006, as a network of observation posts run by hunters during the hunting season. At sites selected by active hunters, wood pigeons were hunted and birds passing the site were counted simultaneously.

The counting routine consisted in recording flocks of wood pigeons using a few standard parameters: the number of pigeons by flock (flock size), direction of flight (according to the standard direction of the local migration stream and 'reverse migration', in the opposite direction), and the bag from the hunting. In this paper, flock size and bag numbers are not taken into account, but they can be used in future work. 
Table 1 presents the periods of work, numbers of sites, numbers of observation days per season, and total numbers of pigeons observed. The observations were carried out essentially day by day, but due to Italian hunting law there were breaks in observation activity two days a week (Tuesday and Friday), when hunting is prohibited (Fig. 1). This meant that the 'continuous day by day' scheme was in fact a kind of sampling method. This resulted in less accurate data for determining the peak days of migration in a season. However, as the total data used cover ten seasons 1998-2006 (the 1997 season is excluded due to incomplete data), at a general level the results should be sufficiently accurate. Another parameter of the observation scheme that was insufficiently standardized was the number of observation sites operating each year. To analyse compatible values, the numbers of birds observed were recalculated to number/site/day and presented for the administrative regions (Tab. 2, Fig. 3). The regions are grouped into three areas from the north to the south of Italy.

\section{I "NUMERI " DELL'AUTUNNO 1997}

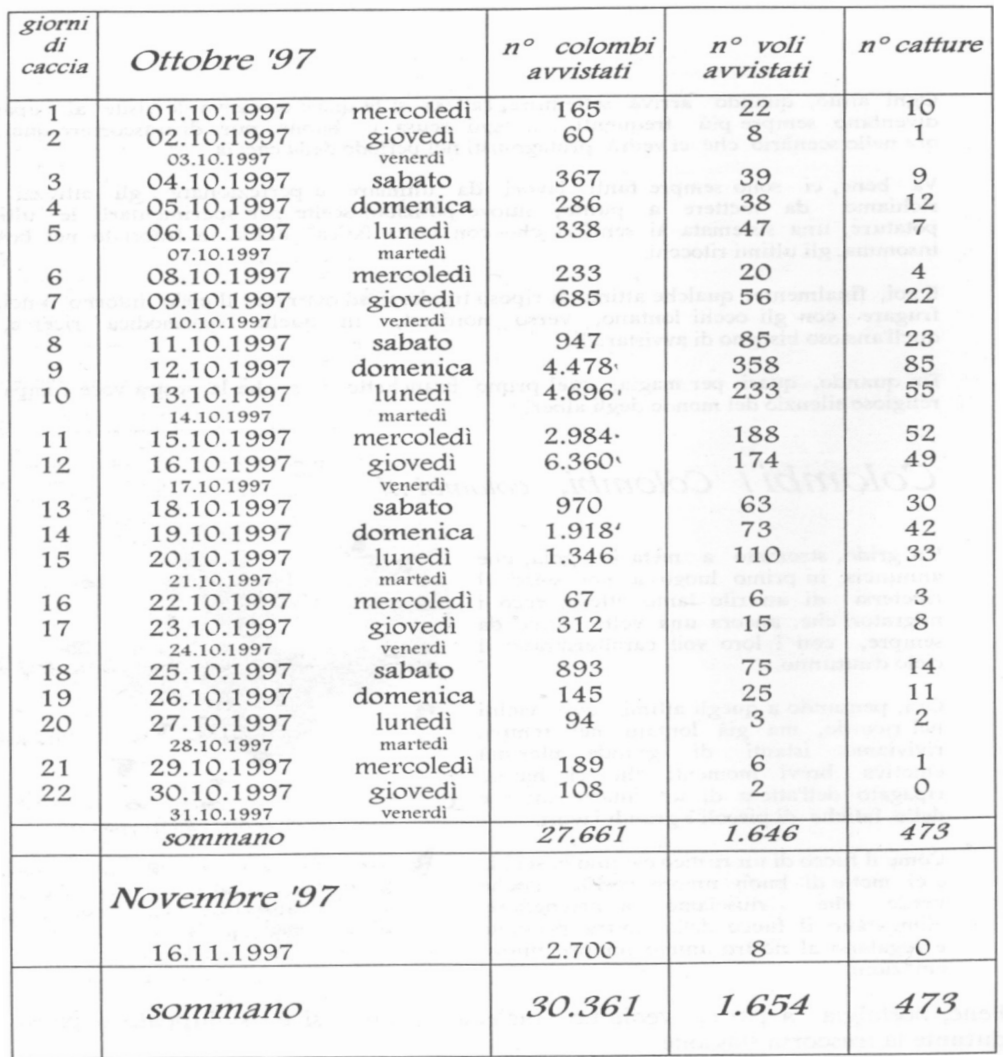

Fig. 1. Example of source data sheet for Italy in 1997 (total, limited data). Numbering of hunting days is given in the first column, then dates (note dates of days without hunting/ observations), followed by numbers of pigeons flying in normal direction of the passage, numbers for reverse movements and numbers of birds shot. 


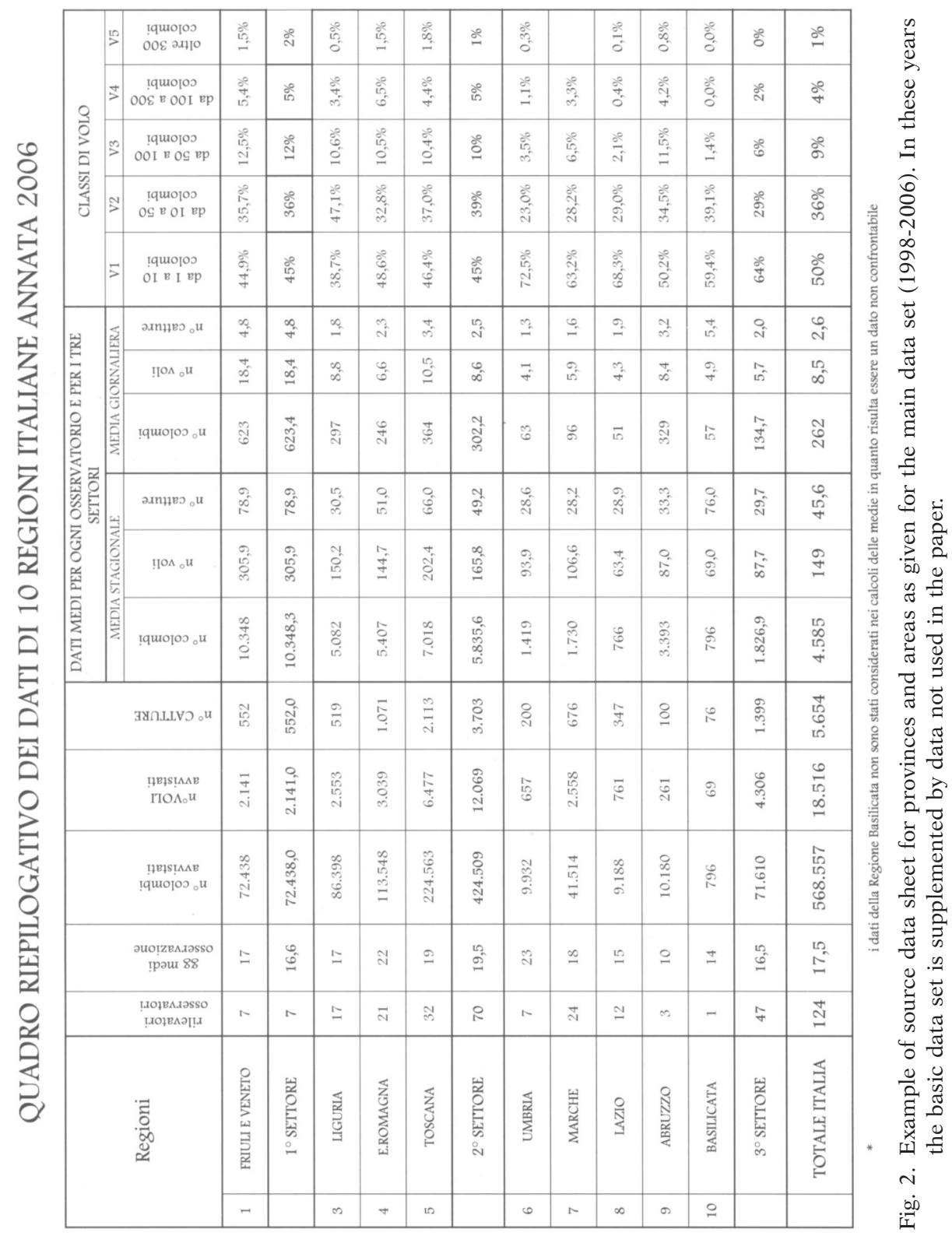


Table 1

Data used in the analysis: number of observation sites, period of work, number of observation days and number of pigeons observed following the migration direction

\begin{tabular}{|c|c|c|c|c|}
\hline Year & $N$ sites & Period of work & $N$ days & $N$ observed \\
\hline 1997 & - & 1 Oct-31 Oct & 22 & 27,661 \\
\hline 1998 & 60 & 26 Sep-5 Nov & 27 & 178,400 \\
\hline 1999 & 100 & 25 Sep-18 Nov & 40 & 349,587 \\
\hline 2000 & 107 & 25 Sep-19 Nov & 40 & 507,175 \\
\hline 2001 & 113 & 25 Sep-18 Nov & 40 & 588,385 \\
\hline 2002 & 124 & 25 Sep-17 Nov & 39 & 807,867 \\
\hline 2003 & 138 & 24 Sep-16 Nov & 39 & 703,758 \\
\hline 2004 & 129 & 22 Sep-11 Nov & 34 & 820,464 \\
\hline 2005 & 143 & 21 Sep-17 Nov & 41 & 489,878 \\
\hline 2006 & 124 & 23 Sep-12 Nov & 37 & 568,557 \\
\hline Total & & & 359 & $5,041,732$ \\
\hline
\end{tabular}

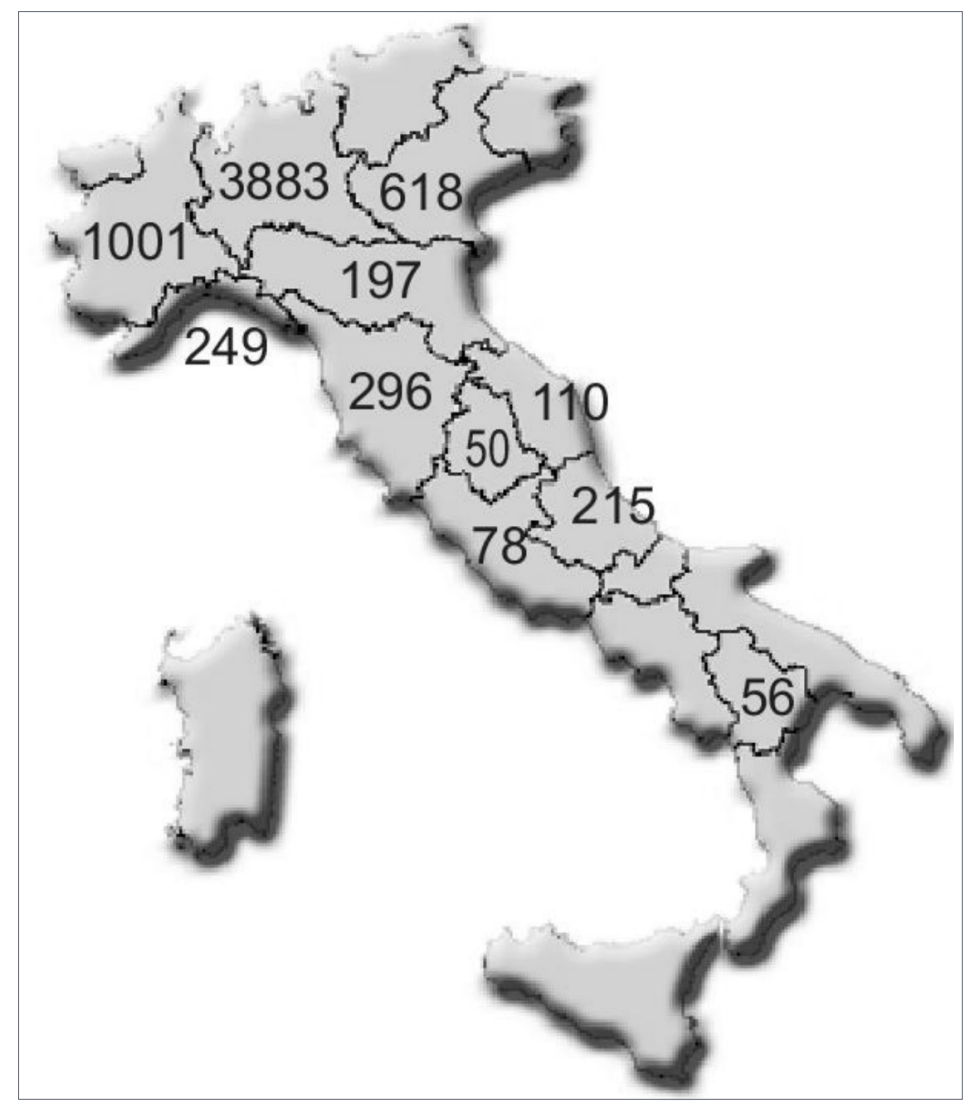

Fig. 3. Average daily numbers of migrating pigeons in different provinces of 
Table 2

Basic data by provinces and areas. Yearly raw numbers of observed pigeons, numbers of observation sites, numbers of observation days and standardized values: number per site and number per site and day

\begin{tabular}{|c|c|c|c|c|c|c|c|c|c|}
\hline AREA I & 1998 & 1999 & 2000 & 2001 & 2002 & 2003 & 2004 & 2005 & 2006 \\
\hline Friuli/Veneto & 43224 & 22283 & 47817 & 53736 & 130641 & 99176 & 134712 & & 72438 \\
\hline Sites & 4 & 5 & 8 & 6 & 7 & 8 & 11 & & 7 \\
\hline Days & 15 & 17 & 15 & 20 & 18 & 19 & 15 & & 17 \\
\hline $\mathrm{N} /$ site & 10806 & 4457 & 5977 & 8956 & 18663 & 12397 & 12247 & & 10348 \\
\hline N/Site/Day & 720 & 262 & 398 & 448 & 1037 & 652 & 816 & & 609 \\
\hline Lombardy & & 25171 & 47894 & 140110 & 153435 & 144816 & 229309 & & \\
\hline Sites & & 2 & 1 & 3 & 4 & 5 & 3 & & \\
\hline Days & & 17 & 13 & 17 & 13 & 8 & 8 & & \\
\hline $\mathrm{N} /$ site & & 12586 & 47894 & 46703 & 38359 & 28963 & 76436 & & \\
\hline N/Site/Day & & $\mathbf{7 4 0}$ & 3684 & 2747 & 2951 & 3620 & 9555 & & \\
\hline Piemonte & & 33563 & 20550 & 4375 & 7150 & 7056 & & & \\
\hline Sites & & 2 & 2 & 1 & 1 & 2 & & & \\
\hline Days & & 8 & 7 & 9 & 14 & 8 & & & \\
\hline $\mathrm{N} /$ site & & 16782 & 10275 & 4375 & 7150 & 3528 & & & \\
\hline N/Site/Day & & 2098 & 1468 & 486 & 511 & 441 & & & \\
\hline \multicolumn{10}{|l|}{ AREA II } \\
\hline Liguria & 8229 & 76667 & 62986 & 71223 & 201075 & 120681 & 92393 & & 86398 \\
\hline Sites & 3 & 16 & 15 & 19 & 20 & 21 & 20 & & 17 \\
\hline Days & 26 & 23 & 24 & 21 & 21 & 19 & 19 & & 17 \\
\hline $\mathrm{N} /$ site & 2743 & 4792 & 4199 & 3749 & 10054 & 5747 & 4620 & & 5082 \\
\hline N/Site/Day & 106 & 208 & 175 & 179 & 479 & 302 & 243 & & 299 \\
\hline E. Romana & 41540 & 66300 & 79719 & 63210 & 80438 & 93411 & 115136 & & 113548 \\
\hline Sites & 20 & 17 & 22 & 18 & 24 & 27 & 26 & & 21 \\
\hline Days & 17 & 19 & 18 & 19 & 19 & 17 & 19 & & 22 \\
\hline $\mathrm{N} /$ site & 2077 & 3900 & 3624 & 3512 & 3352 & 3460 & 4428 & & 5407 \\
\hline N/Site/Day & 122 & 205 & 201 & 185 & 176 & 204 & 233 & & 246 \\
\hline Toscany & 65770 & 89022 & 176790 & 209367 & 163488 & 171310 & 159257 & & 224563 \\
\hline Sites & 17 & 25 & 26 & 30 & 27 & 25 & 24 & & 32 \\
\hline Days & 17 & 21 & 19 & 21 & 22 & 24 & 19 & & 19 \\
\hline $\mathrm{N} /$ site & 3869 & 3561 & 6800 & 6979 & 6055 & 6852 & 6636 & & 7018 \\
\hline N/Site/Day & 228 & 170 & 358 & 332 & 275 & 286 & 349 & & 369 \\
\hline \multicolumn{10}{|l|}{ AREA III } \\
\hline Umbria & 1071 & 2883 & & 2536 & 2648 & 6730 & 12797 & & 9932 \\
\hline Sites & 1 & 5 & & 5 & 5 & 8 & 9 & & 7 \\
\hline Days & 15 & 20 & & 16 & 16 & 19 & 18 & & 23 \\
\hline $\mathrm{N} /$ site & 1071 & 577 & & 530 & 530 & 841 & 1422 & & 1419 \\
\hline N/Site/Day & 71 & 29 & & 33 & 33 & 44 & 79 & & 62 \\
\hline Marche & 7624 & 11862 & 28554 & 13948 & 28337 & 34619 & 56257 & & 41514 \\
\hline Sites & 3 & 8 & 11 & 9 & 11 & 21 & 20 & & 24 \\
\hline Days & 15 & 23 & 19 & 24 & 22 & 20 & 19 & & 18 \\
\hline $\mathrm{N} /$ site & 2541 & 1483 & 2596 & 1550 & 2576 & 1649 & 2813 & & 1730 \\
\hline N/Site/Day & 169 & 64 & 137 & 65 & 117 & 82 & 148 & & 96 \\
\hline Lazio & 9149 & 16922 & 34598 & 25009 & 32120 & 23406 & 17107 & & 9188 \\
\hline Sites & 11 & 16 & 20 & 20 & 21 & 18 & 13 & & 12 \\
\hline Days & 12 & 16 & 17 & 17 & 17 & 15 & 16 & & 15 \\
\hline $\mathrm{N} /$ site & 832 & 1058 & 1730 & 1250 & 1530 & 1300 & 1316 & & 766 \\
\hline N/Site/Day & 69 & 66 & 102 & 74 & 90 & 87 & 82 & & 51 \\
\hline Abruzzo & 1793 & 4814 & 8267 & 4871 & 7870 & 2137 & 2474 & & 10180 \\
\hline Sites & 1 & 1 & 2 & 2 & 3 & 2 & 2 & & 3 \\
\hline Days & 10 & 15 & 13 & 15 & 14 & 11 & 11 & & 10 \\
\hline $\mathrm{N} /$ site & 1793 & 4814 & 4134 & 2436 & 2623 & 1069 & 1237 & & 3393 \\
\hline N/Site/Day & 179 & 321 & 318 & 162 & 187 & 97 & 112 & & 339 \\
\hline Basilicata & & & & & 665 & 416 & 1022 & & 796 \\
\hline Sites & & & & & 1 & 1 & 1 & & 1 \\
\hline Days & & & & & 11 & 15 & 13 & & 14 \\
\hline $\mathrm{N} /$ site & & & & & 665 & 416 & 1022 & & 796 \\
\hline N/Site/Day & & & & & 60 & 28 & 79 & & 57 \\
\hline
\end{tabular}


The general presentation of the course of seasonal migration through Italy is based on raw numbers of daily migrating birds, as well as an analysis of variation in the course of the seasonal migration pattern. It is common knowledge among students of the seasonal pattern of passage of birds, irrespective of the species, that dayto-day numbers of migrants are typically extremely variable. Rushes of migration are noted in which more than $25 \%$ of the yearly number of migrants of a given species pass the observation site in one day, and fluctuations from one day to the next can reach $1,000 \%$ or more. Various terms have been used for such rushes, usually peaks or waves of migration, but frequently the precise meaning of these terms is not defined. The terms are commonly explained as 'a day or days with clearly higher frequency in the course of the seasonal migration pattern'. This makes comparisons of patterns difficult.

In this paper, we define the term peak day as a day within which the number of observed birds exceeds $5 \%$ of the individuals observed within the season (all birds observed from the beginning to the end of the observation period $=100 \%$ ). This means that if during a period of two, three or more consecutive days the share of birds each day is above $5 \%$ of the total number of observed birds, all these days will be called 'peak days'. For a more precise description, peak days with different values are designated as 'low peaks' $-5.1-10.0 \%$ of the yearly total, 'moderate peaks' $-10.1-15.0 \%$ and 'high peaks' - $>15 \%$. Still the term 'peak' refers to one day. When we use the percentage value of the share of the day in the entire study, calculation of the Similarity Index (SI - discussed below) is natural and easily understandable.

We use the term wave of migration to refer to a period of several days in sequence in which the migration is more intensive than in periods with lower numbers (shares). The wave can contain both peak days and days with very low numbers. Within the entire period of seasonal migration, waves are usually smaller at the beginning and at the end of migration period than in the middle period of migration, and of course the probability that real peak days will occur then is lower.

To study whether two curves representing migration dynamics are similar or dissimilar in terms of the course of migration, we can use statistical tools, such as chisquare or similarity indices. The similarity index used in this paper is the Renkonen coefficient:

$$
S I=\operatorname{Sum} \min \left[n \%_{\mathrm{d} 1}, n \%_{\mathrm{d} 2}\right] \text {, }
$$

where: $S I$ is the sum of minima in the daily pair of frequency values expressed as a percentage of the total samples compared ( $\mathrm{n} \% \mathrm{~d} 1, \mathrm{n} \% \mathrm{~d} 2)$. The Renkonen coefficient is commonly used to compare species population structure in botanical and zoological ecology. The logical and statistical structure of our problem exactly fits the assumptions of the Renkonen coefficient. Since in this paper the data for establishing the dates of peaks of migration were recalculated to daily percentage values, the results were ready to use for calculation of $S I$ values. In this study, $S I$ values were calculated to define the similarity of the migration dynamics in each year to the average dynamics for all ten years together. The level of statistical significance of the results was estimated by comparing the $S I$ values with those obtained in a detailed study of the problem by Nowakowski et al. (2005), where the same method was used. The same proce- 
dure could be used to compare the synchrony of migration through different areas in Italy, but available data are still too limited.

\section{RESULTS}

\section{Intensity of migration and multi-year number trends}

The basic results for intensity of migration at sites situated in different areas and provinces of Italy are presented in Table 2 and Figure 3. The most intensive migration is observed within Area I in the northern part of Italy, where pigeons move over fairly open and flat landscapes, while lower intensity is visible more to the south of the Italian peninsula, where birds must travel along several valleys to cross the Apennine Mountains.

Examination of the tendencies in numbers of observed migrants within the tenyear study period reveals positive tendencies in most of the northern provinces, while three negative trends are visible in the central part of Italy (Fig. 4). Thus trends for

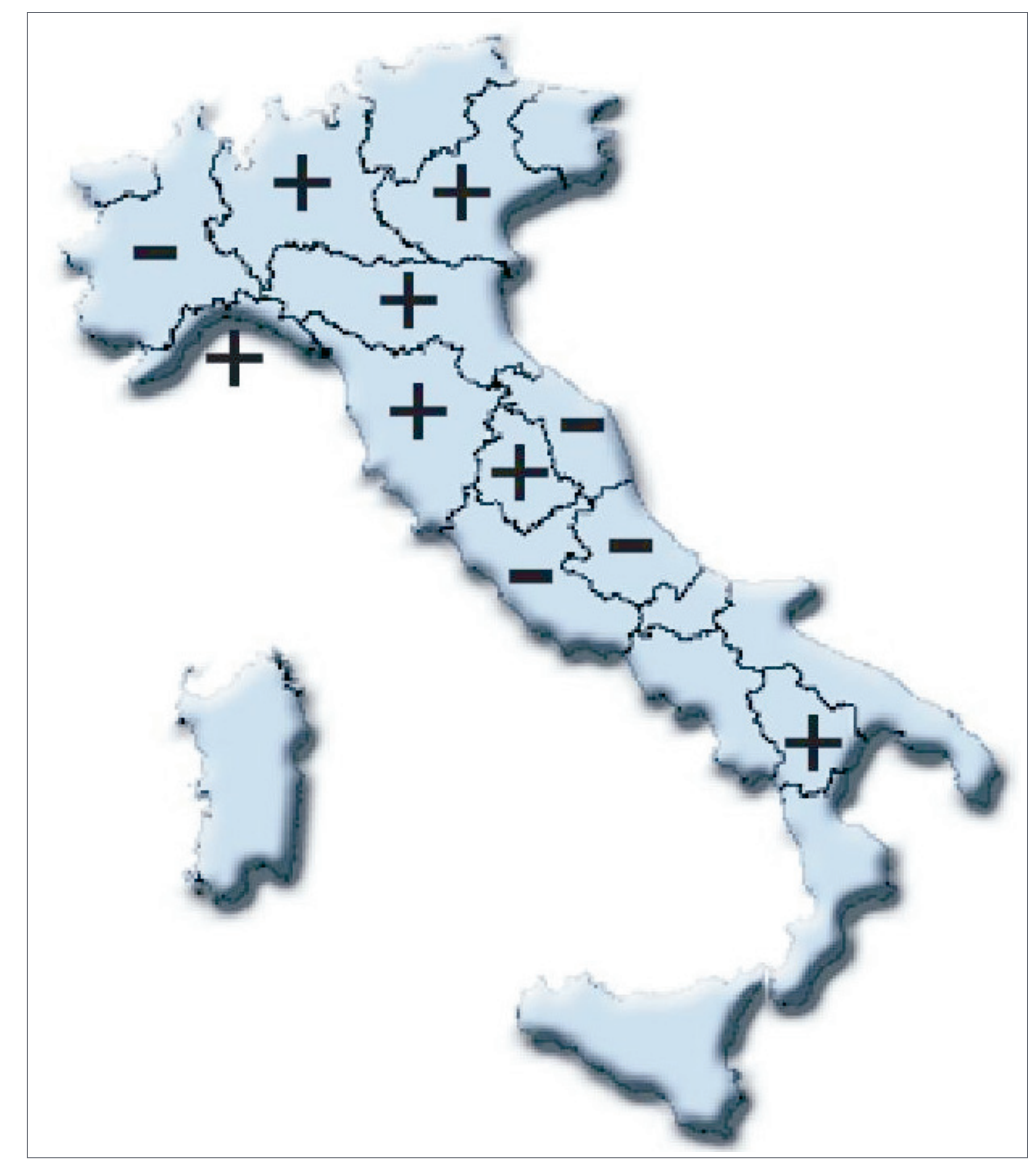

Fig. 4. Trends in numbers of pigeons as observed in different provinces 
Areas I and II are positive (Fig. 5). The regression coefficient for Area II is statistically highly significant $\left(p<0.01, F_{6}=18.25\right)$, while for Area I it is not $\left(p>0.05, F_{6}=1.35\right)$. Note, however, that the slope is similar to that of Area II, and the lack of formal significance is due to the high variation within the data for that area (especially in 2004, when the number of birds observed far surpassed the numbers in other years). The trend for Area III is slightly, insignificantly negative $\left(p>0.05, F_{6}=0.29\right)$. At this time the number of birds observed in Area I is one order higher than in Areas II and III.
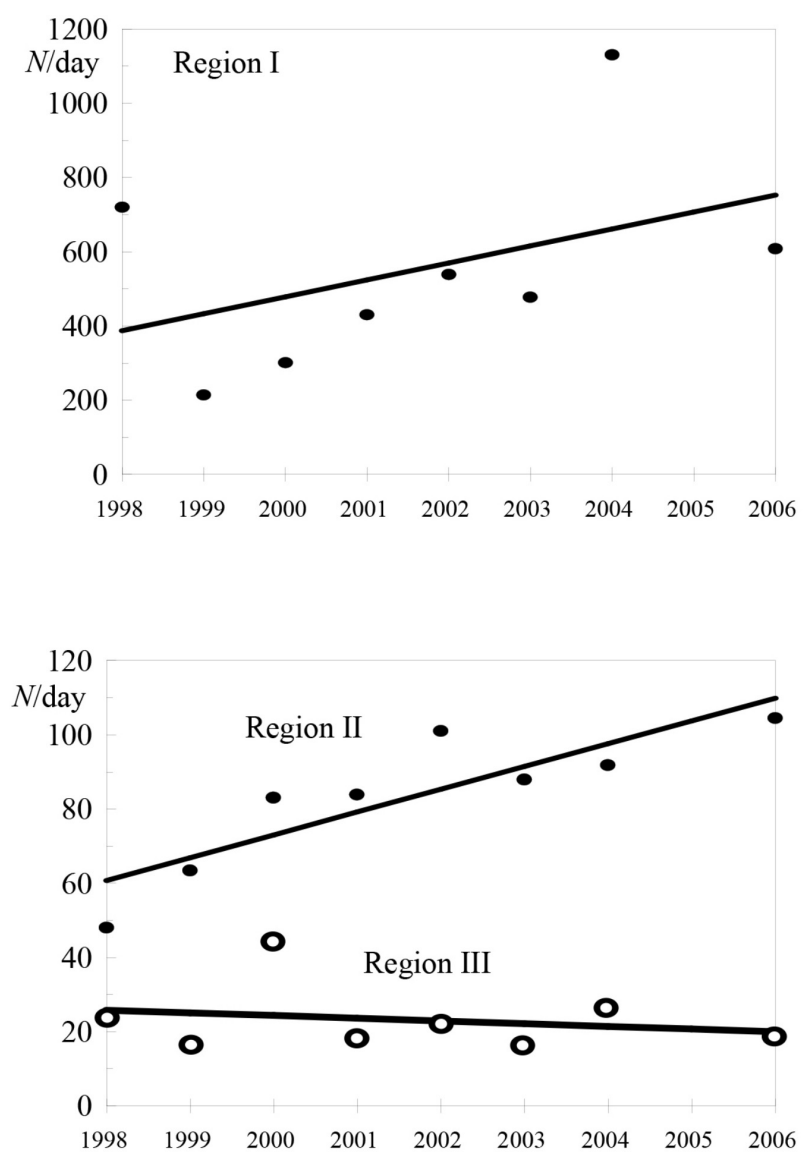

Fig. 5. Total number trends in 1998-2006 by areas. Dots - yearly values (number per day), lines regression equation lines

\section{Seasonal dynamics}

Traditionally, when the sampling method is used, records are grouped to obtain a more general picture. In this way, Figure 6 shows the general pattern of the autumn migration of wood pigeons as one maximum, but asymmetric curve of the number of observed individuals. The shape of the distribution pattern of migration peaks is very 
similar. Both show clearly that the distribution is not normal, but probably composed of a few basic normal or quasi-normal distributions caused by internal group differentiation (migration in several migratory waves).

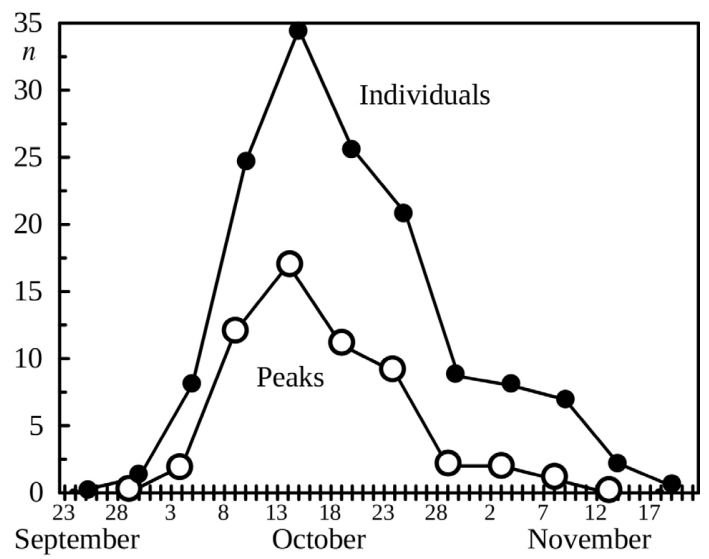

Fig. 6. Seasonal pattern of Wood Pigeon migration in Italy presented traditionally as numbers (Individuals - per station and day) grouped into pentades [5-day periods] (line with black circles) and as number of peaks in these pentades (line with empty circles)

A more detailed - day-by-day - analysis of the distribution of numbers and peaks confirms this supposition (Fig. 7). Both distributions show a clear multi-wave pattern. Comparison of these distributions using the $S I$ (Similarity Index) gives an extremely high $S I$-value of 85.6, which is significant at the level of at least $p<0.001$ (Nowakowski et al. 2005). Thus only day-by-day analysis is suitable for studying the problem of peaks and waves of migration. Distributions of peak days in different years are presented in Figure 8, where yearly patterns are shown against the background of the total pattern of migration.

The next step of the analysis is to answer the question, 'are the yearly patterns based on a common, repeatable general migration pattern?' The first verification that the distribution of peaks corresponds to the basic structure of migration has already been presented in Figure 7, where the curves for the number distribution as well as the peak distribution clearly show at least five waves (a sixth wave is probably hidden in an asymmetric first wave at the beginning of the distribution). The second argument is even stronger - the analysis of the similarity of the yearly patterns with a common template of migration shows that all yearly courses of migration dynamics are in highly significant agreement ( $p$ at least at the 0.001 level) with the average course of migration (Table 3). This table also shows that the variance in $S I$-values for different years is quite low ( $A v g=67.7, S D=6.01$, coefficient of variation $V=8.87$ ). Comparison of the data in this table also shows that the number of birds observed at the average site influences the $S I$-value less (Pearson's $r=0.61, p>0.05$ ) than the number of sites $(r=0.75, p<0.05)$. This underscores the importance of the number of observation sites when studying details of the migration dynamics pattern. 

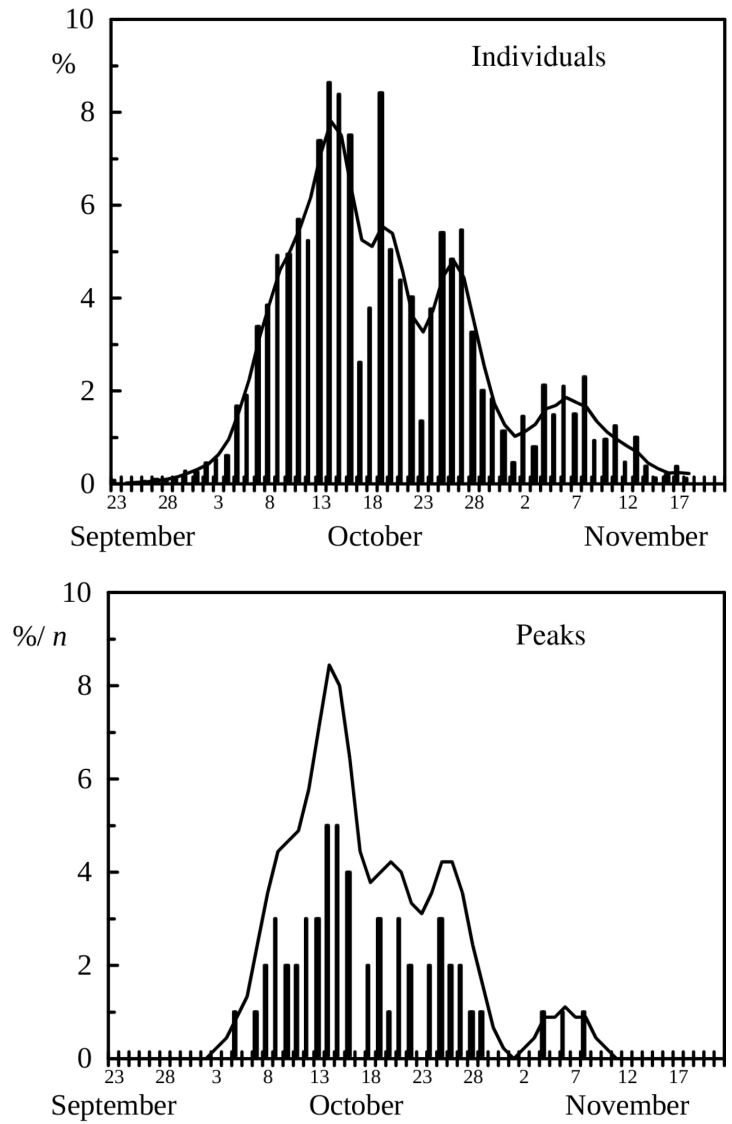

Fig. 7. Left panel: day-by-day total seasonal pattern of migration - numbers: bars - average daily numbers of pigeons (per station and day) for the whole 1998-2006 period, expressed for year as percentage share of the yearly total, line - daily data smoothed by 5 -day moving average.

Table 3

Similarity Indices for yearly seasonal dynamics of the pigeons' passage. Numbers of observation sites and average numbers of birds observed per site in year are given.

\begin{tabular}{|c|c|c|c|}
\hline Year & Sites & Pbserved & Similarity \\
\hline 1998 & 60 & 2973 & 58.4 \\
\hline 1999 & 100 & 3496 & 59.3 \\
\hline 2000 & 107 & 4718 & 65.6 \\
\hline 2001 & 113 & 5207 & 69.3 \\
\hline 2002 & 124 & 6517 & 64.6 \\
\hline 2003 & 138 & 5074 & 72.8 \\
\hline 2004 & 129 & 6360 & 78.6 \\
\hline 2005 & 143 & 3407 & 69.4 \\
\hline 2006 & 124 & 4585 & 69.7 \\
\hline Avg & $\mathbf{1 1 5}$ & $\mathbf{4 ~ 7 0 4}$ & $\mathbf{6 7 . 5}$ \\
\hline SD & $\mathbf{2 3 . 5}$ & $\mathbf{1 ~ 1 8 2}$ & $\mathbf{6 . 0 1}$ \\
\hline
\end{tabular}




\section{DISCUSSION AND CONCLUSIONS}

In-depth studies on seasonal differentiation in the intensity of migration are relatively scarce. Frequently the problem of a very high level of fluctuations in numbers of observed/caught individuals of migrating species is treated as a stochastic variation caused by the unpredictable influences of various physiological properties of birds, sensitivity to weather, habitat, and climate. This kind of explanation of the peaks and breaks observed in seasonal dynamics patterns is convincing mainly when the data
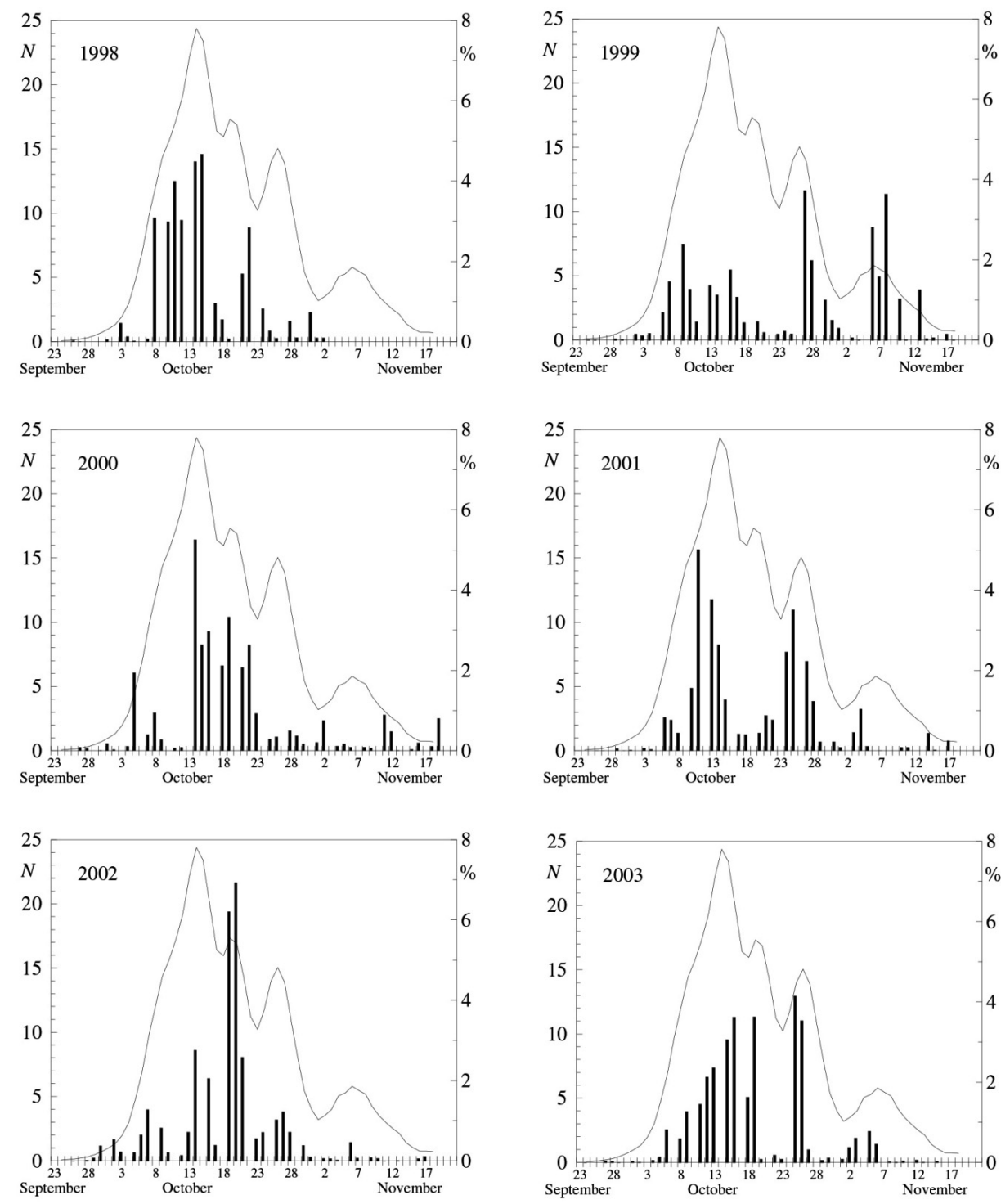

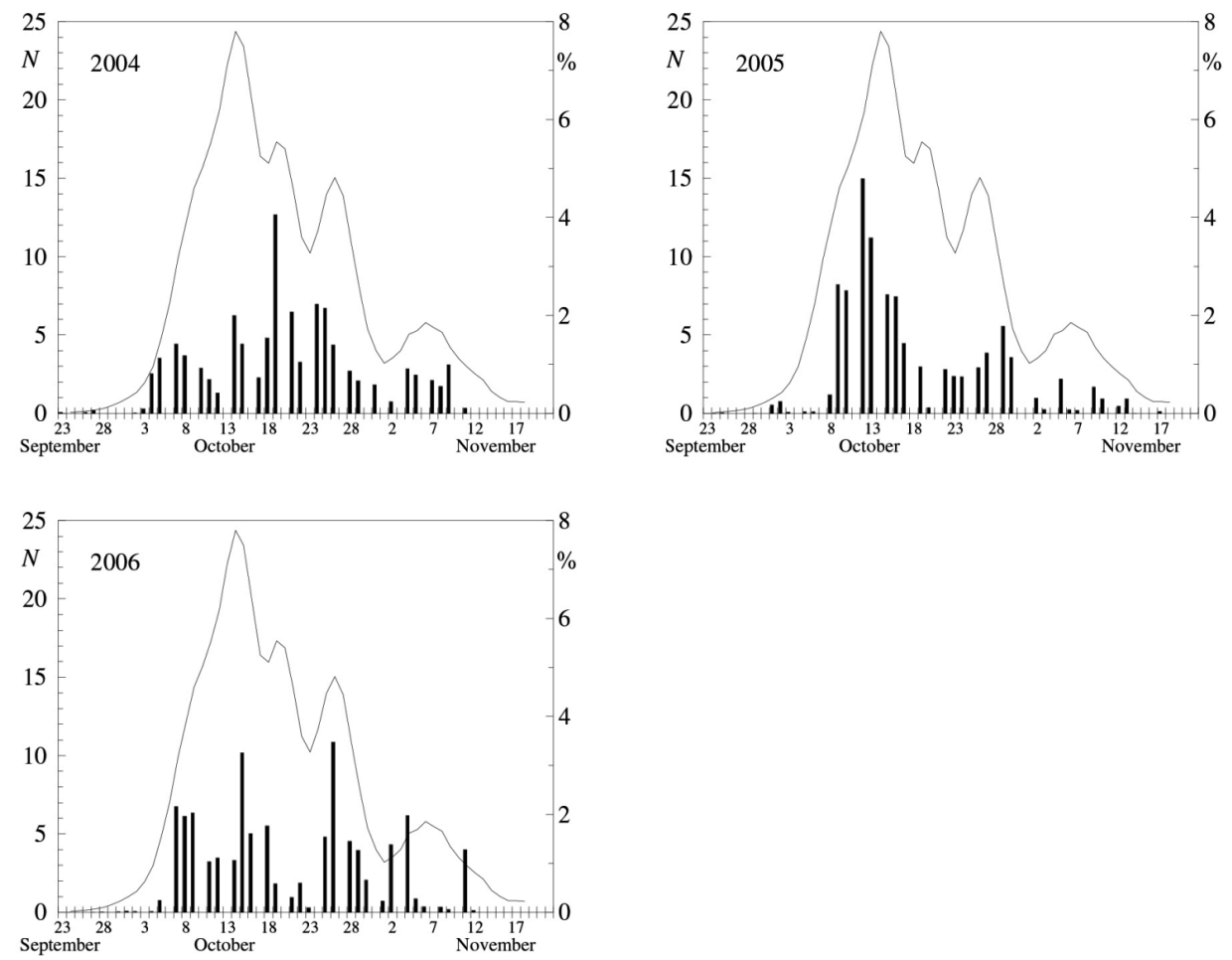

Fig. 8. Time distribution of migratory peaks (bars - left scale) within certain years shown against a background of the general migration pattern (line - right scale - corresponds to smoothed percentage pattern in Figure 7 - left panel)

come from single years or a short time series. If the time series is long enough, the stochastic variation should lead to a chaotic distribution of peaks in the summarized seasonal patterns, most likely in a form close to the Gaussian, normal distribution (if only one bird population is passing the observation site). In the most common case, when we have different populations (in terms of source areas, destination winter quarters and/or direction of migration), a general normal distribution is very unlikely. This is very well confirmed by the long-term data (since 1961) of Operation Baltic in Poland, e.g. ten years of data for many species ringed/observed - Busse and Halastra 1981; thirty years of data for the Willow Warbler Pylloscopus trochilus - Piotrkowska 1995 and for the Blackcap Sylvia atricapilla - Busse 1996, Kopiec 1997, Kopiec-Mokwa 1999; and fourteen years of data for the Robin Erithacus rubecula - Nowakowski et al. 2005, as well as data from other areas, e.g. a nineteen-year study on many species from Hungary - Gyuracz et al. 2017, or a ten-year study of many species from Palestine - Awad et al. 2017. There are many, many examples of multi-wave distributions. Thus the results obtained in the current study suggesting several waves in the seasonal dynamics of the Wood Pigeon are very well grounded.

Here we have five or six groups of pigeons passing through Italy in different parts of the autumn, and the time of the passage, including a few peak days, is quite 
stable between years. Yearly peaks in different waves, as well as the waves themselves, are not regularly of the same relative number sizes, but it is quite normal that different groups of migrants have their own number size and migration variation.

The general problem here that should be solved in the future is what the waves found for pigeons really mean. If, as is common in many bird species within the Baltic area, directions of migration are differentiated (e.g. Goldcrest - Busse 1981, Remisiewicz and Baumanis 1996), the waves could contain different migratory populations migrating one by one or they may be composed of a mix of individuals belonging to different migratory populations (Busse and Maksalon 1978). Birds migrating the same way, but with various areas of origin, can form more or less uniform waves migrating sequentially - as was supposed for the Coal Tit migrating in the 1974 irruption (Busse 1978). This was suggested by some signs of separation mechanisms during observations of movement through a few bird stations along the Baltic coast. A similar case was found for the Goldcrest on the central part of the Polish Baltic coast (Busse 1981). Finally, Blyumenthal (1971) explained the typical occurrence of waves in migration as the result of bioenergetic mechanisms. From the general population pattern of migration of Wood Pigeon in central and southern Europe (Fig. 9) estimated on the basis of analysis of radioisotopes (Hobson 2009) and bird recovery atlases for Italy (Spina and Volponi 2008), the Czech Republic and Slovakia (Cepák et. al. 2008), and Germany (Bairlein et al. 2014), we can rule out the formation of subsequent waves by different migratory populations (birds from the southern flow vs.

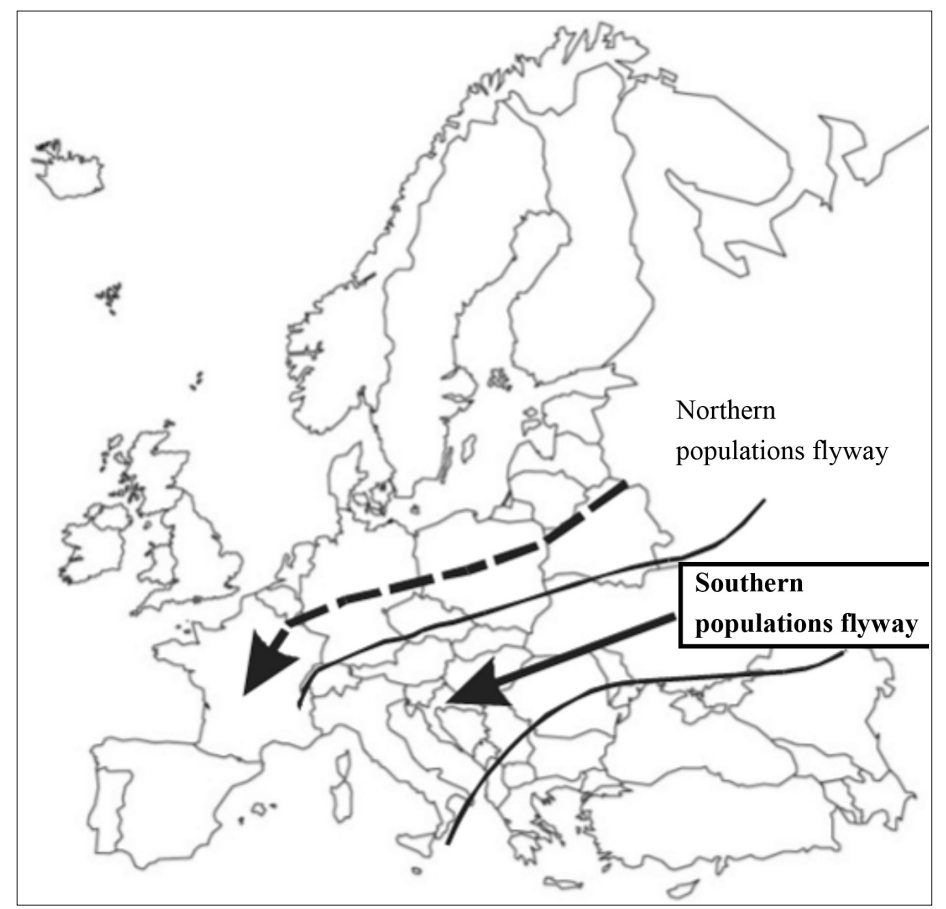

Fig. 9. General spatial pattern of Wood Pigeon migration in Europe as a rough estimation from stable isotopes analysis and bird recovery atlases (cited in the text). 
those belonging to the northern flow). Therefore, what we have in the area studied is a wave structure caused by sequential starts of groups originating in more or less distant territories along the same flyway; or, any mechanism that sorts birds according to inherited migration distance may play the main role in the creating the wave. Inherited tendencies may, however, be modified by climate change and/or selection pressure, as shown for partial migrants. Which explanation better fits wood pigeon migration is to be discovered in the future, as it could be important for sustainable exploitation of the pigeon as a hunting resource.

Because our data for Italy are very general, it is not yet possible to discuss whether these populations travel over the entire country or pass over different regions. We still we do not know whether we have been studying different subpopulations or the entire stream is differentiated only by the time of migration of subgroups of inhabitants of the same area. Another problem with the seasonal dynamics awaiting more in-depth study is the occurrence of peak days of migration within waves of migration. Valuable attempts to study the causes of peaks observed in migration are presented online by Cavina (2015) and seem to be worthy of further work. Therefore we need more data, from more years and more sites in various regions, to be able to draw a detailed picture of the wave and population structure of pigeon migration.

\section{ACKNOWLEDGEMENTS}

We would like to express our gratitude to all members/observers from Club Italiano Colombaccio. The data collection would not have been possible without their cooperation.

\section{REFERENCES}

Awad S.I., Farhoud M. H. and Saada Abu R. K. 2017. Long-term bird ringing in Palestine. Ring 39: 83-102.

Bairlein F., Dierschke J., Dierschke V., Salewski V., Geiter O., Hüppop K., Köppen U. and Fiedler W. 2014. Atlas des Vogelzugs. Aula-Verlag Wiebelsheim.

Blyumenthal T. I. 1971. The development of the autumnal migratory state in some wild Passerine birds: bioenergetic aspect. In: Ekologiceskye i fizyologiceskyie aspekty piereletow ptic: 111-182. Leningrad.

Busse P. 1978. Wave and population structure during Coal Tit autumn migration in 1974. Not. Orn. 19, 1-4: 15-36.

Busse P. 1981. Finding of local passage direction as the result of an analysis of retraps and short distance direct-recoveries. Not. Orn. 22: 3-4.

Busse P. 1996. Modelling of the seasonal dynamics of bird migration. Ring 18, 1-2: 97-119.

Busse P. and Halastra G. 1981. The autumn migration of birds on the Polish Baltic sea coast. Acta orn. 18, 3: 167-290.

Busse P. and Maksalon L. 1978. Some aspects of Song Thrush migration at Polish Baltic coast. Not. Orn. 19, 1-4: 1-14.

Cavina E. 2015. Decision making of autumn migrations of woodpigeons (Columba palumbus) in Europe: analysis of the abiotic factors and atmospheric pressure changes. www. scienceheresy.com/ornithologyheresy/Cavina 2015

Cepák J., Klvaňa P., Škopek J., Schöpfer L., Jelínek M., Hořák D., Formánek J. and Zárybnický J. 2008. Czech and Slovak Bird Migration Atlas. Aventinum, Praha. 
Gyurácz J., Bánhidi P., Góczán J., Illés P., Kalmár S., Koszorús P., Lukács Z., Németh C. and Varga L. 2017. Bird number dynamics during the post-breeding period at the Tömörd Bird Ringing Station, western Hungary. Ring 39: 23-82.

Hobson, K. A., H. Lormée, S. L. Van Wilgenburg, L. I. Wassenaar, and J. M. Boutin. 2009. Stable isotopes (?D) delineate the origins and migratory connectivity of harvested animals: The case of European woodpigeons. Journal of Applied Ecology 46: 572-581.

Kopiec K. 1997. Seasonal pattern of the Blackcap (Sylvia atricapilla) autumn migration at the Polish Baltic coast. Ring 19, 1-2:41-58.

Kopiec-Mokwa K. 1999. Dates of migration waves - a coincidence or an effect of biologically based mechanism? Improvement of the method of analysing the seasonal migration dynamics. Ring 21, 2: 131-144.

Piotrkowska L. 1995. [Analysis and comparison of the dynamics of autumn migration of Willow Warbler (Phylloscopus trochilus) at Bukowo, Hel and Vistula Spit.] Diploma work at University of Gdańsk, Poland. (in Polish)

Remisiewicz M., Baumanis J. 1996. Autumn migration of Goldcrest (Regulus regulus) at the eastern and southern Baltic coast. Ring 18, 1-2: 3-36

Nowakowski J.K., Remisiewicz M., Keller M., Busse P. and Rowiński P. 2005. Synchronisation of the autumn mass migration of passerines: a cse of Robins Erithacus rubecula. Acta orn. 40, 2: 103-115.

Spina F, Volponi S (2008) Atlante della Migrazione degli Ucelli in Italia. 1. non-Passeriformi. Ministero dell'Ambiente e della Tutela del Territorio e del Mare, Istituto Superiore per la Protezione e la Ricerca Ambientale (ISPRA). Tipografia SCR-Roma 